\title{
Predictive validity of pressure ulcer risk assessment tools in intensive care patients
}

Eman S.M. Shahin, RN; BSc, MSc, PhD student, Department of Nursing Science, Centre of Humanities and Health Sciences, Charité, Universitätsmedizin, Berlin, Germany;

Theo Dassen, RN; PhD, Professor, Director of Department of Nursing Science, Center of Humanities and Health Sciences, Charité, Universitätsmedizin, Berlin, Germany;

Ruud J.G. Halfens, PhD, Associate Professor, Health Care Studies/Nursing Science Section, Faculty of Health Sciences, Universiteit Maastricht, The Netherlands.

E-mail: eman.shahin@charite.de

Key Words: assessment tools * intensive care * pressure sore * pressure ulcer * risk assessment

\section{SUMMARY}

- $\quad$ Risk assessment scales are considered essential in pressure ulcer prevention. It is therefore important to use appropriate pressure ulcer risk assessment scales.

- The research question for this study was: what is the predictive validity of pressure ulcer risk assessment tools for intensive care patients?

- Design: review of the literature from 1981 to 2005 regarding the predictive validity of pressure ulcer risk assessment scales in intensive care patients.

- Results: only one risk scale was found for intensive care patients, namely the 'Cubbin and Jackson' scale which is a modification of the Norton scale. The method of evaluating the predictive validity of pressure ulcer risk assessment scales applied in the remainder of the scales was not suitable. In addition, none of the studies considered any factors that can affect the validity of the scale, such as the use of preventive measures or the patients' general conditions and the level of nursing care.

- Conclusions: There is no effective pressure ulcer risk assessment scale described in literature. When evaluating the content validity with percentage values, expert agreement is often criticised, because there is a risk of exaggerated values caused by chance agreement. More statistical methods related to validity and reliability and the choice of appropriate cut-off points of the pressure ulcer risk assessment scale have to be used to enhance the evaluation of the predictive validity of the risk scales. Pressure ulcer risk assessment scales in intensive care settings should include the general health condition, the level of nursing care and an appropriate cut-off point. It is suggested that it is required to combine risk scales and clinical judgement.

\section{INTRODUCTION}

Risk assessment scales are considered essential in pressure ulcer prevention (European Pressure Ulcer Advisory Panel Guidelines, 2001). There is a consensus that the prevention of pressure ulcers should include mechanisms for predicting those patients who are more likely to develop pressure ulcers than others are and that interventions should be directed for people at a high risk of having pressure ulcers (Defloor \& Grypdonck, 2004). Therefore, it is important to use appropriate pressure ulcer risk assessment scales.

An appropriate risk scale is based on the analysis of the patient characteristics making it possible to identify patients who are indeed at risk and need intensified prevention. A perfect scale is easy to use, reliable and valid for prospective studies but also cost-effective in terms of preventive measures (Keller et al. 2002). Reliability can be defined as something that represents the consistency of measures obtained (Burns \& Grove, 2001). The validity of risk assessment scales demonstrates the range of discussions regarding the extent to which each instrument actually measures the risk of developing pressure ulcers. However, validity has been discussed in the literature in terms of content validity, predictive validity and construct validity as well. The various types of validity are very confusing, especially because they are not discrete but interrelated (Burn \& Grove, 2001). In addition, validity and reliability are not independent qualities of an instrument. A measuring instrument that is unreliable cannot possibly be valid (Burns \& Grove, 2001; Polit \& Beck, 2004). A perfect risk assessment scale for pressure ulcers with the aforementioned characteristics should therefore be designed in such a way that it is appropriate for patients with different health conditions in different health care settings.

In order to evaluate a risk instrument two criteria have to be used reliability and validity (Polit \& Beck, 2004). Reliability is measured in two ways: internal consistency, for which the Cronbach's Alpha co-efficient is commonly used, and stability over certain periods of time, which is measured by means of test-retest reliability (Cutcliffe \& Mckenna, 2002). In addition, the equivalence of the instrument is measured by means of inter-rater reliability and interpretive reliability. By using interpretive reliability we can assess the extent to which each judgement assigns the same category to a given unit of data. However, a more desirable method of calculating the extent of agreement between judgments is the Cohen's Kappa statistic (Burns \& Grove, 2001).

The second criterion is the validity (accuracy) of the scales. Furthermore, the content validity could be quantified by using three stages including a development stage consisting of three steps: the first being the domain of content by means of a comprehensive review of literature and/or consultation with content experts; the second step is items generation; and the third step is that of constructing the instrument by an appropriate 
wording of items. Stage two is the judgement/quantification stage that requires a panel of content experts to validate the items with regard to the domain of content and measures the percentage of agreement of experts who have evaluated the relevance of the instrument and its items (Wynd \& Schaifer, 2002). Additionally, the construct validity can be measured by using the factor analysis (Polit \& Beck. 2004).

Another difficult task is to develop the appropriate cut-off point for the risk scale. Therefore, the researchers often use the so-called ROC (receiver operating curve) as a statistical method to detect cut-off points (Polit \& Beck. 2004). It is also important to empirically calculate the relation between the instrument and the concept "risk of developing pressure ulcers" (predictive validity) (Halfens, 2000). As stated by Pender and Frazier (2005), patients in intensive care settings are almost entirely at risk of developing pressure ulcers. This study investigates the reliability and validity of risk assessment scales in intensive care.

\section{Research question}

- What is the predictive validity of pressure ulcer risk assessment tools for intensive care patients?

\section{METHODOLOGY}

A search was conducted through CINAHL, PubMed and the Cochran Library from 1981 to 2005. The key words used were different combinations of pressure ulcer, pressure sore, decubitus ulcer, bed sore on the one hand and risk factors, assessment tool (or instrument), predictive validity (validity and/or reliability) and intensive care unit (ICU) on the other hand. The inclusion criteria were articles in English and German dealing with the assessment of pressure ulcer risk factors in adult intensive care patients and reporting on the validity, reliability and predictive validity of pressure ulcer risk assessment tools in intensive care patients. The exclusion criteria were risk assessment tools in paediatric or other health care settings. The abstracts of the relevant articles were reviewed based on the above inclusion criteria. There were 729 articles. 227 articles were found in Pub med, 500 in CINAHL and two articles in the Cochran library.

\section{RESULTS}

The results of this search strategy resulted in 722 articles that did not fulfil the inclusion criteria, that is some did not measure the validity and/or the reliability or predictive validity of pressure ulcer risk assessment scales or the scales were tested in paediatric patients, other health care settings or the articles were not written in English nor German. Only seven of the articles dealt with the predictive validity of pressure ulcer risk assessment scales in intensive care (see Table 1).
Only six risk assessment scales were tested for their predictive validity (Haalboom et al. 1999). Out of these six, the Norton and Waterlow scales were tested twice and the Braden scale on nine different occasions (Schoonhoven et al. 2005). With regard to these scales it can be seen that the Norton scale was initially developed for research in a geriatric population (Lindgren et al. 2002). In addition, it assesses two issues: the psychological issue by assessing the mental status and the physiological issue by assessing continence, mobility, activity and the physical condition. The Braden Scale, however, was derived from the conceptual schema of Braden and Bergstrom (1987) and only assessed the physical issue by means of the following six subscales: mobility, activity, sensory perceptions, skin moisture, nutritional status and friction (shear).

Another scale, called the Douglas Scale (1986), assesses different issues such as the psychological issues by means of the mental status, the physical by means of pain, activity, physical condition, incontinence and the therapeutic issues by means of special risks including steroid therapy, diabetes, cytotoxic therapy and dyspnoea (Keller et al. 2002). A further risk scale is the Waterlow Scale, which was developed by Waterlow in 1985 and includes six subscales each dealing with a risk factor associated with the presence of pressure ulcers and four special risk categories detailing the presence of high risk factors (Papanikolaou et al., 2002). The Cubbin and Jackson scale was developed by Cubbin and Jackson (1991) for use in intensive care patients. It includes ten variables (age, weight, general skin, mental condition, mobility, haemodynamic status, respiration, nutrition, incontinence and hygiene) (Jackson, 1999). The study by Bergstrom et al. (1987) on the predictive validity of the Braden Scale revealed that the sensitivity of the Braden Scale in adult intensive care patients was $83 \%$ while the positive predictive validity was $60.6 \%$. On the other hand, the specificity was $64 \%$, while the negative predictive validity was $85 \%$. Beekman et al. (1996) found out that the sensitivity of the Braden scale in orthopaedic ICU patients was $89 \%$ compared to the positive predictive validity which was $84.8 \%$. The specificity value was $88 \%$ and the negative validity value was $91.2 \%$. The study by Fife et al. (2001) in neurological intensive care patients established that the Braden Scale had a high sensitivity but a low positive predictive validity. Moreover, when a cut-off score of 16 was used, the false negative value was $0 \%$, but the false positive value was $81.9 \%$ and therefore accuracy was only $44.1 \%$.

The study by Van den Bosch et al. (1996) in intensive care, general care and in inpatient rehabilitation wards revealed that the sensitivity and specificity of the Braden Scale were equal while the negative predictive validity value was twice as high as the positive predictive validity. However, the study by Weststrate et al. (1998) in surgical intensive care units regarding the predictive validity of the Waterlow scale revealed that the Waterlow scale had a high sensitivity but a low specificity. The

\begin{tabular}{|c|c|c|c|c|c|c|c|c|}
\hline Scale & $\begin{array}{l}\text { Author and } \\
\text { year of } \\
\text { publication }\end{array}$ & Setting & Design & Sample size & Sensitivity & Specificity & $\begin{array}{l}\text { Positive } \\
\text { predictive } \\
\text { validity }\end{array}$ & $\begin{array}{l}\text { Negative } \\
\text { predictive } \\
\text { validity }\end{array}$ \\
\hline Braden Scale & $\begin{array}{l}\text { Bergstrom et } \\
\text { al. (1987) }\end{array}$ & ICU & Clinical trail & 60 & 83 & 64 & 61 & 85 \\
\hline Braden Scale & $\begin{array}{c}\text { Beekman et al. } \\
(1996)\end{array}$ & $\begin{array}{l}\text { Orthopaedic } \\
\text { ICU }\end{array}$ & & 42 & 89 & 88 & 84.8 & 91.4 \\
\hline Braden Scale & $\begin{array}{l}\text { VandenBosch } \\
\text { et al. (1996) }\end{array}$ & ICU & $\begin{array}{l}\text { Longitudinal } \\
\text { study }\end{array}$ & 103 & 59 & 59 & 36.1 & 78.6 \\
\hline Waterlow Scale & $\begin{array}{c}\text { Weststrate } \\
(1998)\end{array}$ & Surgical ICU & $\begin{array}{c}\text { Prospective } \\
\text { study }\end{array}$ & 594 & 80 & 29 & 9 & 95 \\
\hline Braden Scale & Fife et al. 2001 & $\begin{array}{c}\text { Neurological } \\
\text { ICU }\end{array}$ & Cohort study & 186 & 91.4 & Not mentioned & 27.3 & Not mentioned \\
\hline $\begin{array}{l}\text { - Braden Scale } \\
\text {-Cubbin and Jackson } \\
\text { - Douglas Scale }\end{array}$ & $\begin{array}{l}\text { Seongsook et } \\
\text { al. } 2004\end{array}$ & ICU & $\begin{array}{l}\text { Longitudinal } \\
\text { study }\end{array}$ & $\begin{array}{l}112 \\
112 \\
112\end{array}$ & $\begin{array}{c}79 \\
89 \\
100\end{array}$ & $\begin{array}{l}26 \\
61 \\
18\end{array}$ & $\begin{array}{l}37 \\
51 \\
34\end{array}$ & $\begin{array}{c}95 \\
92 \\
100\end{array}$ \\
\hline $\begin{array}{l}\text {-Braden Scale } \\
\text { - Modified Norton } \\
\text { - 4- factor model }\end{array}$ & $\begin{array}{l}\text { Feuchtinger et } \\
\text { al. (2005) }\end{array}$ & $\begin{array}{c}\text { Cardiac } \\
\text { surgery ICU }\end{array}$ & $\begin{array}{l}\text { Explorative } \\
\text { prospective } \\
\text { study }\end{array}$ & $\begin{array}{l}53 \\
53 \\
53\end{array}$ & $\begin{array}{l}97 \\
58 \\
85\end{array}$ & $\begin{array}{c}5 \\
47 \\
31\end{array}$ & $\begin{array}{l}69 \\
70 \\
70\end{array}$ & $\begin{array}{l}50 \\
35 \\
38\end{array}$ \\
\hline
\end{tabular}

Table 1. Studies examining the predictive validity of pressure ulcer risk assessment scales in intensive care patients 
positive predictive validity was also very low while the negative predictive validity was relatively high $(95 \%)$.

Seongsook et al. (2004) tested three different risk assessment scales in intensive care patients, namely the Braden, the Cubbin and Jackson and the Douglas scales and found out that the scale with the highest sensitivity was the Douglas Scale with $100 \%$, but the latter also had the lowest specificity, the highest negative predictive validity and the lowest positive predictive validity. The highest positive predictive validity and specificity was that of the Cubbin and Jackson scale. On the other hand, the Braden scale had the lowest sensitivity. In addition, we observed only little differences between the values of the negative predictive validity of the Braden Scale and the Cubbin and Jackson Scale. Feuchtinger et al. (2005) have recently found out that the Braden scale, the modified Norton scale and the 4-factor model were not valid as pressure ulcer risk assessment scales for intensive care patients. It was also established that the lowest specificity value was that of the Braden Scale (5\%), although it had the highest sensitivity (97\%). Furthermore, the negative predictive validity for all three scales was low (ranging from $50 \%$ to $35 \%$ ).

\section{DISCUSSION}

It can be seen that the majority of studies testing the predictive validity of pressure ulcer risk assessment scales only used the sensitivity and specificity as a method to measure the predictive validity. Furthermore, regarding the study results there is a fluctuation in the values of sensitivity and specificity which also lead to a fluctuation in the positive and negative predictive validity. As stated by Defloor and Grypdonck (2004), a good risk assessment scale should have both a high sensitivity and a high specificity.

The sensitivity of an instrument is the rate of yielding true positives, while the specificity is the rate of yielding true negatives. Moreover, when sensitivity is increased to include more true positives, the number of true negatives declines at the same time (Polit \& Beck, 2004).

There is more than one factor affecting the accuracy of the aforementioned tests, that is, the standard or the level of nursing care. Intensive care patients are, however, a special population in that their general health condition significantly contributes to the development of pressure ulcers. In addition, not all preventive measures can be used in intensive care settings, a fact to always be aware of.

Furthermore no other means of measuring the reliability of pressure ulcer risk assessment scale were used, such as the Cronbach's alpha for internal consistency or the Cohen's Kappa statistics for inter-rater reliability, except in the study by Halfens et al. (2000). Furthermore, the study of Seongsook et al (2004) was the only one using the receiver operating curve (ROC) as a method to detect the appropriate cut-off point of the risk scale. The studies did not use factor analysis as an evaluation method for the construct validity. Therefore, the cut-off point used was different in each study, for example in one study the cut-off point used was 18 while it was 19 or 20 in another study. This led to changes in the study results and also the values of the predictive validity of the risk scale. The studies did not take in consideration either the use of any preventive measures. This means, preventive measures were not excluded in the studies, nor were they measured by the pressure ulcer risk assessment scales. Therefore, there is a risk, which an increased use of preventive measures could interfere with and which could also influence the results regarding the sensitivity of the scale, meaning they could be lower due to the better care given to the patients.

On the other hand, the risk assessment scales were designed to identify patients at risk of developing pressure ulcers (Keller et al. 2002). In that respect, we were therefore able to detect differences in the studies between the theoretical domain of the scale and the practical domain. As mentioned above, the theoretical domain identifies patients at risk of developing pressure ulcers; however, the practical domain did not identify patients at risk of developing pressure ulcer but only those patients who had already developed a pressure ulcer. Furthermore, most of the developed risk assessment scales reflect expert opinions, literature reviews or adaptations of existing scales (Schoonhoven et al., 2005), which means the content validity of those scales is based on the extent to which experts agree on the relevant instrument and its items. However, agreement and proportion agreement are often criticised because there is a risk of exaggerated values caused by chance agreement (Wynd \& Schaifer, 2002).

The Cubbin and Jackson Scale was the only one designed for intensive care patients and it also is a modification of the Norton scale that includes some items relevant to intensive care patients such as the haemodynamic status or respiration (Jackson, 1999). Patients in many intensive care units are, however, usually sedated and ventilated and therefore unable to move or care for themselves (Lowery, 1995).

The predictive validity of all studies on pressure ulcer risk assessment scales in intensive care settings was evaluated by testing their sensitivity, specificity, positive predictive validity as well as negative predictive validity. The studies of Bergstrom et al. (1987) revealed that both the Braden and Norton scales were predicting pressure ulcers excessively. However, the excessive prediction of the Norton scale was estimated at $64 \%$ while it was $36 \%$ for the Braden scale. This difference is clinically important if all patients, who have been considered to be at risk, receive additional nursing care or protective devices. A larger number of patients may also have received unnecessary and expensive treatments when the Norton scale was used, which leads to an increase in costs. Furthermore, Fife et al. (2001) revealed that the Braden scale was more effectively used in neurological intensive care units. The risk of pressure ulcers increased when the Braden score decreased. The effectiveness of the Braden scale was also based on the time the patient was assessed and on the cut-off point used. This means if the patient was assessed upon admission or one day later and a cut-off point of 18,19 or 20 was used, the effectiveness of the scale may be influenced. No cut-off point can guarantee anyway that in a large population all patients at risk are separated from those who are not at risk, therefore a residual risk must be accepted if a cut-off point is used.

Van den Bosch et al. (1996) stated that there was no significant difference whether or not the nurses correctly predicted the risk of developing pressure ulcers, in contrast to the Braden Scale was the most highly significant finding between the pressure ulcer positive and pressure ulcer negative groups. There are several approaches that can affect the evaluation of the predictive validity of the risk assessment scales. First, there is the ethical consideration, according to which the ethical unacceptability of withholding prevention makes it difficult to evaluate the predictive validity of risk assessment scales. Unfortunately, an ideal value is not readily available. Preventive measures can also affect the true and false positive values and/or true and false negative values and have a negative effect on the validity of the scale. Another approach is a clinical one, that is, the main benefit of using a risk assessment scale lies in the fact that it reminds nurses of the possibility of a developing pressure ulcer.

The fourth approach is to start prevention as soon as a non-blanchable erythema is observed (Defloor \& Grypdonck, 2004). Such an approach does not differ from frequently applied common practice. Furthermore, when evaluating the validity of risk assessment scales, we should not only describe and discuss the preventive measures provided to patients at risk but also the standard nursing care. Therefore, both preventive care and standard care have to be similar in all test settings in order to obtain comparable results. If we find that the preventive care is the same in all settings but the level of care provided is different and vice versa, then this may lead to different results and therefore to different conclusions.

On the other hand, Seongsook et al. (2004) found out that the Cubbin and Jackson Scale showed the best validity of all scales (Douglas and Braden) and was therefore recommended for intensive care patients. As stated by Seongsook et al. (2004), these scales were used on patients within 48 to 72 hours after admission, which may decrease the accuracy of the predictive validity of the scales, because the conditions of intensive care patients are not stable and can often change from one day to the next or even from hour to hour.

Weststrate et al. (1996) state that the development of a pressure ulcer is also a product of time and pressure in combination with a number of predisposing intrinsic and extrinsic factors. According to them, a pressure ulcer can develop within between one to five days. So it may be useful 


\section{* Predictive validity of pressure ulcer risk assessment tools in intensive care}

patients *

and more accurate to assess patient risk for pressure ulcer upon their admission and also frequently thereafter.

Notwithstanding, Boyle \& Green (2001) established that both the Cubbin and Jackson and the Waterlow scales only poorly predicted pressure sores in intensive care patients, whereas Weststrate et al. (1998) found that most categories in the Waterlow scale were confirmed to have an influence on the development of pressure sores. Moreover, the combination of the categories and weighting of the various category items were based on a study of the relevant literature and discussions with other health care professionals. This process was clinically confirmed in this study. The scale was designed as an instrument to warn care providers of pressure ulcer risk levels in patients and not to predict whether or not the patient will inevitably develop a pressure sore. So the use of this evaluation method is different from other pressure sore risk scales calculating the sensitivity and specificity of a threshold score at which a patient will definitely develop a pressure sore.

Theaker et al. (2000) also established that the Norton scale and the Waterlow scale were more appropriate for general wards and had to be considerably modified for a potential use in the population of critically ill patients. When used for intensive care patients, the scores tend to predict pressure sore development excessively. Weststrate et al. (1996) also stated that it cannot be definitely confirmed that the Waterlow Scale can be used effectively to measure the risk of patients developing a pressure sore. In addition, Feuchtinger et al. (2005) reported that the predictive validity of the Norton Scale, the Braden Scale and the 4-factor model was poor, because some variables are, for example, not included in the Norton Scale, although they are relevant to the ICU population, such as shear and friction, or activity, nutrition and mobility, which are missing in the 4-factor model. If one of the variables is not included in an instrument, it is not measured and cannot predict pressure ulcer development. Nevertheless, sensitivity and specificity, which constitute the ability of the scale to differentiate correctly between patients at risk and those not at risk, are unsatisfactory for all scales. This results in the following questions:

- What is a pressure ulcer risk assessment scale supposed to measure?

- What are the criteria of an ideal risk assessment scale?

- What are the characteristics actually measured with pressure ulcer risk assessment scales in practice?

- How good are the tests used to evaluate the predictive validity of pressure ulcer risk assessment scales?

\section{CONCLUSIONS}

Having reviewed the articles about the predictive validity of pressure ulcers in intensive care it can be concluded that the majority of risk assessment scales are not developed for intensive care patients in particular, and that the Cubbin and Jackson Scale, a modification of the Norton Scale, was the only one actually developed for intensive care patients. In addition, the tests that are used to evaluate the predictive validity, sensitivity, specificity, positive predictive validity and negative predictive validity are not quite suitable for pressure ulcer risk assessment scales, because they do not give an accurate evaluation, as they do not take into consideration the use of any preventive measures. Furthermore, some scales were tested in intensive care settings, but the predictive validity differed in each study.

In order to obtain a valid pressure ulcer risk assessment scale for intensive care patients we should also assess the preventive measures that are actually applied in an intensive care setting and be aware of all factors influencing the evaluation of the risk scale, such as the patient's general health conditions, the level of nursing care, and the cut-off point of the risk scale. We also have to define what exactly it is we want to measure with the risk scale. A suggestion is to combine pressure ulcer risk assessment scales with the nursing staff's clinical judgement in order to achieve a possibly more predictive statement.

\section{REFERENCES}

Beekman EP, Timmermans PPH, Halfen RJG. (1996). De Bradenschaal.Validiteit en betrouwbaaheid van een meetinstrument voor het risico van decubitus (The Braden Scale. Validity and reliability of a pressure ulcer risk assessment tool). Verpleegkunde 11, 205-214.

Bergstrom N, Demuth PJ, Braden BJ. (1987). A clinical trail of the Braden scale for predicting pressure sore risk. Nursing Clinics of North America 22 (2), 417-428.

Boyle M, Green M. (2001). Pressure sores in intensive care: defining their incidence and associated factors and assessing the utility of two pressure sore risk assessment tools. Australian Critical Care 14 (1), 24-30.

Burns N, Grove SK. (2001). The Concepts of Measurement; In: The Practice of Nursing Research Conduct, Critique and Utilization, $4^{\text {th }}$ Edition. Saunders Company, Philadelphia, USA.

Cutcliffe JR, Mckenna HP. (2002). When do we know that we know? Considering the truth of research findings and the craft of qualitative research. International Journal of Nursing Studies 39 (6), 611-618.

European Pressure Ulcer Advisory Panel. (2001). Pressure ulcer prevention guidelines; 3(3) [online]. Available at: http://www.epuap. org/prevention.html [Accessed 21 April 2006].

Defloor T, Grypdonck MFH. (2004).Validation of pressure ulcer risk assessment scales: a critique. Journal of Advanced Nursing 48 (6), 613-621.

Feuchtinger J, Halfens RJG, Dassen T. (1998). Pressure ulcer risk assessment in the early postoperative ICU- after cardiac surgery - does it meet the goal? Intensive and Critical Care Nursing 25 (1), 36-43.

Fife C, Otto G, Capsuto E.G, Brandt K, Lyssy K, Murphy K, Short C. (2001). Incidence of pressure ulcers in a neurological intensive care unit. Critical Care Medicine 29 (2), 283-290.

Halfens RJG. (2000). Risk assessment scales for pressure ulcers: a theoretical, methodological and clinical perspective. Ostomy Wound Management; 46 (8), 36-44.

Haalboom JRE, Den Bore J, Buskens E. (1999). Risk assessment tools in the prevention of pressure ulcers. Ostomy Wound Management 45 (2), 20-34.

Halfens RJG, Achterberg TV, Bal RM. (2000). Validity and reliability of the Braden scale and the influence of the risk factors: a multi-centre prospective study. International Journal of Nursing Studies 37 (4), 313-319.

Jackson C. (1999). The revised Jackson/Cubbin pressure area risk calculator. Intensive and Critical Care Nursing 15 (3), 169-175.

Keller BP, Wille J, Ramshorst BV, Werken C. (2002). Pressure ulcer in intensive care patients: a review of risks and prevention. Intensive Care Medicine 28 (10), 1379-1388.

Lindgren M, Unosson M, Krantz A, Christina A. (2002). A risk assessment scale for the prediction of pressure sore development: reliability and validity. Methodological Issues in Nursing Research 38 (2), 190-199.

Papanikolao P, Clark M, Lyne PA. (2002). Improving the accuracy of pressure ulcer risk calculators: some preliminary evidence. International Journal of Nursing Studies 39 (2), 187-194.

Lowery MT. (1995). A pressure sore risk calculator for intensive care patients: the Sunderland experience. Intensive and Critical Care Nursing 11 (6), 344-353.

Pender L, Frazier SK. (2005). The relationship between dermal pressure ulcers, oxygenation and perfusion in mechanically ventilated patients. Journal of Intensive and Critical Care Nursing 21 (1), 19-8.

Polit DF, Beck CT. (2004). Assessing Data Quality In: Nursing Research: Principles and Methods, $7^{\text {th }}$ Edition. Lippincott Williams \& Wilkins Company, Philadelphia. 
Schoonhoven L, Haakboom JRE, Bousema MT, Algra A, Grobbee DE, Grypdonck MH, Buskens E. (2002). Prospective cohort study of routine use of risk assessment scales for prediction of pressure ulcers. BMJ 325 (7368), 797-801.

Seongsook J, Innsook J, Younghee L. (2004). Validity of pressure ulcer risk assessment scales; Cubbin and Jackson Braden scale and Douglas scale. International Journal of Nursing Studies 41 (2) 199-204.

Theaker C, Mannan M, Ives N, Soni N. (2000). Risk factors for pressure sores in the critically ill. Anaethesia 55 (3), 221-224.

Weststrate JTM, Bruining HA. (1996). Pressure sores in an intensive care unit and related variables: a descriptive study. Intensive and Critical Care Nursing 12 (5), 280-284.
Weststrate JTM, Hop WCJ, Aalbers AGJ, Vreeling AWJ, Bruining HA. (1998). The Clinical Relevance of The Waterlow Pressure Sore Risk Scale in The ICU. Intensive Care Medicine 24 (8), 815-820.

Wynd CA, Schaifer MA. (2002).The osteoporosis risk assessment tool: Establishing content validity through a panel of experts. Applied Nursing Research 16 (2), 184-188.

Vandenbosch T, Montoye C, Satwicz M, Durkee-Leonard K, BoylanLewis B. (1996). Predictive validity of the Braden scale and nurse perception in identifying pressure ulcer risk. Applied Nursing Research 9 (2), 80-86.

Van Marum RJ, Ooms ME, Ribbe ME, Van Eijk JT. (2000). The Dutch pressure sore assessment score or the Norton scale for identifying at-risk nursing home patients? Age and Ageing 29 (1), 63-68. 